\title{
BMJ Open How can positive and negative trainer feedback in the operating theatre impact a surgical trainee's confidence and well- being: a qualitative study in the north of England
}

Dariush Kamali, Jan Illing

To cite: Kamali D, Illing J. How can positive and negative trainer feedback in the operating theatre impact a surgical trainee's confidence and wellbeing: a qualitative study in the north of England. BMJ Open 2018;8:e017935. doi:10.1136/ bmjopen-2017-017935

- Prepublication history for this paper is available online. To view these files, please visit the journal online (http://dx.doi. org/10.1136/bmjopen-2016017935).

Received 29 May 2017 Revised 22 September 2017 Accepted 3 November 2017
Check for updates

School of Medical Education, SME Research Unit, The Medical School, Newcastle University, Newcastle upon Tyne, UK

Correspondence to Dr Dariush Kamali; dariush.kamali@nhs.net

\section{ABSTRACT}

Objective To identify the perception of positive feedback (PF) and negative feedback (NF) provided by trainers in the operating theatre on surgical trainees' confidence and well-being.

Design Narrative interview study.

Setting Twelve hospitals that form part of one deanery within the UK.

Participants Maximum variation sampling of 15 higher general surgical trainees provided insight into how PF and $\mathrm{NF}$ from trainers in the operating theatre affect confidence and well-being.

Methods Narrative telephone interviews were conducted with general surgical trainees between April and June 2016. All interviews were recorded, transcribed and anonymised. Transcriptions were analysed using the five-step framework analysis by two independent researchers.

Results Fifteen trainees (age 28-38 years) were interviewed (median interview time: $29 \mathrm{~min}$ ). Thematic framework analysis identified nine themes within the data. PF, which included corrective feedback, helped the trainees to relax and seemed to enhance their operative performance. All trainees reported significant and unjustified NF, some of which would be defined as undermining and bullying. Many believed this to have a negative impact on their training with minimal educational benefit. Many trainees felt NF adversely affected their performance in the operating theatre with some expressing a wish to leave the profession as a consequence.

Conclusion Both PF and NF exist in the operating theatre. Both have an important influence on the trainee, their performance and career. PF, if specific, helped aid progression of learning, increased motivation and performance of surgical trainees. In contrast, NF was perceived to have detrimental effects on trainees' performance and their well-being and, in some, introduced a desire to pursue an alternative career.

\section{INTRODUCTION}

Feedback is one of the most powerful influences on learning. A large meta-analysis
Strengths and limitations of this study

- This is the first study that describes the impact of positive and negative feedback towards general surgical trainees in the operating theatre regarding its effects on their confidence, well-being and further development.

- This study used a narrative approach to identify the issues involved rather than count frequency of experiences that would lack depth and understanding.

- The study was limited to one training region and therefore may not be representative of all surgical trainees elsewhere in the UK. However, existing research on bullying suggests that the study findings do have national relevance.

concluded that feedback is more powerful than a student's prior cognitive ability. ${ }^{1}$ The importance of feedback provision in medical education, training and professional development has been emphasised for more than 30 years. ${ }^{2}$ However, historically within medicine, the recognition and acquisition of feedback by doctors has been poor. $^{3}$

Both positive and negative feedback can enhance the learning process. Positive feedback can increase the likelihood that students will return to or persist in an activity and self-report higher interest in an activity. ${ }^{4}$ Negative feedback can have a powerful effect on an individual's self-control, self-direction and self-discipline. ${ }^{1}$ However, if negative feedback is in excess, it can have the opposite effect and undermine an individual's subsequent performance. ${ }^{56}$

The majority of feedback within the context of surgery relates to improving one's skills ${ }^{7}$ or its impact following the introduction of a feedback intervention 
tool, ${ }^{8}$ rather than its impact on the trainee themselves. There is paucity within the literature describing the effect that verbal feedback can have on surgical trainee's development and well-being. Research has shown that those with low existing levels of self-esteem are more likely to react poorly to negative feedback, exhibiting less motivation on a subsequent task and believing that the feedback received is due to ability rather than effort. ${ }^{9-11}$ If this is the case for surgical trainees, it may result in poorer operative performance with potential compromise on patient safety and quality of care.

The aim of this research was to identify the narrative accounts of receiving positive and negative feedback from trainers in the operating theatre on a general surgical trainee's personal and professional development, potentially identifying areas in which improvements can be made to surgical training.

\section{Research questions}

1. What forms of positive and negative verbal feedback are surgical trainees exposed to in the operating theatre?

2. How can positive or negative verbal feedback affect a surgeons' training and personal development?

3. Why does negative feedback exist in the operating theatre environment?

\section{Definitions}

The definition of what constituted positive or negative feedback was determined by the participants. From the researchers' perspective, positive feedback was defined as information provided to the trainee in a supportive and constructive manner (which could include corrective feedback) with the aim of improving their performance and personal well-being. Furthermore, negative feedback was presumed to be information, adverse behaviour or mode of feedback provided to the trainee that was felt to be unwarranted and without regard for the individual's well-being (which could be perceived as bullying). However, using a constructivist approach, it was the participants who attributed their own meaning to these terms and shared their constructs with the interviewer.

\section{Relationship of trainers and trainees within a UK system}

Surgical trainers are defined as any consultant who is the senior surgeon and supervisor of trainees within the operating theatre at a particular time. Typically within the UK, all trainees work in the same hospital for 12 months and rotate between different specialties within that hospital every 6 months. Trainees undertake elective and emergency work with different trainers. Therefore, interaction with a trainer can be on a frequent basis if this forms part of their elective work or less frequently, for example, during emergency surgery with a consultant from another specialty within general surgery.

\section{METHODS}

\section{Study design}

A qualitative study was conducted using a narrative technique to elicit the perceptions of positive and negative feedback on surgical trainee's development. Interviews were conducted via telephone. Interviews were selected over focus groups due to the difficulty of getting groups of clinicians together. ${ }^{12}$ In addition, it was felt that revealing personal experiences, particularly of a negative nature, to a group may result in respondents either downplaying their experiences, ${ }^{13}$ or a reluctance to provide details in front of peers who may be perceived as judging them. ${ }^{14}$ This study draws on a social constructionist perspective, given the multiple interpretations of reality and ways of knowing. ${ }^{15}$ Constructivism postulates that learning is an active, constructive process. Through this research, we aimed to collate and construct information regarding the effects of feedback. All information provided by participants was accepted, despite the potential of being contradictory, as multiple equally valid accounts of the effects of feedback can exist.

\section{Sampling and recruitment}

All participants were invited to provide written consent prior to interview and gave verbal consent again at the start of the interview. Sixteen surgical trainees were purposively selected from a total of fifty-four trainees in the region using maximum variation (gender, age, place of work and year of training); this also supported the natural demographic trends from the training programme as a whole. To ensure anonymity, trainee's responses were represented by an identification (ID) number. Trainees were initially personally invited via a generic text message outlining the study aim. Participants were then contacted via telephone and given additional information about the study so as to make an informed decision. One trainee declined to participate in the study as they felt that talking about their experiences may affect their future career. By recruiting higher surgical trainee's specific to general surgery, this would ensure trainees had substantial exposure to the operating theatre. Furthermore, the decision to recruit in general surgery alone was that general surgical trainees have a varied experience and breadth of procedures, so that it was felt unnecessary to include other specialties. The variation of operations would be sufficient to promote a differing range of experiences compared with more specialised areas of surgery. ${ }^{16}$ One of the aims in data collection was to reach data saturation. This varies depending on topic but can be anywhere from 10 to 30 interviews. ${ }^{17}$ In this study, data saturation was achieved after 15 interviews. It was therefore decided by the researchers that further sampling was not necessary. A narrative approach was used for data collection enabling a full account or story to unfold. ${ }^{18}$ 


\section{Data collection}

Participants were purposively selected to take part in this study (using maximum variation). Narrative telephone interviews were conducted between April and June 2016. All interviews were conducted by DK. Interviews took a median time of $29 \mathrm{~min}$ (range 21-50), were tape-recorded, transcribed and anonymised. Interviews began by exploring examples of participant's experiences of receiving both positive feedback and then negative feedback in the operating theatre. Interviews continued until participants felt that they had shared their experiences sufficiently.

\section{Data analysis}

All recorded transcriptions were individually reviewed to ensure quality. Data were analysed using the fivestep framework analysis of: familiarisation, framework development, indexing, charting and mapping. ${ }^{19}$ Development of thematic frameworks was achieved by primary review of interview material, note-making and documentation of differing responses. Initially, interviews were indexed to identify a priori issues. Following subsequent review of more interviews, emergent themes arose by analysing respondent's narrative for unexpected issues and analytic for themes that had explanatory power. Mapping was required to ensure that all relevant information and themes that had emerged from the interviews were detected, with the aim of answering the study questions. To ensure rigour, all transcripts were reviewed at each stage of the analysis by JI. New themes and subthemes were discussed and agreed at each process of analysis.

\section{RESULTS}

Fifteen participants were purposively sampled and interviewed from one region within the UK and included trainees from years 3-8, included 4 females and 11 males. Data collection continued until no new themes were identified.

Framework analysis identified nine themes within the data: two themes (a priori) relating to the first research question (types of positive and types of negative feedback), four themes (emergent) relating to the second research question (positive feedback affecting the self, positive feedback affecting learning, negative feedback affecting the self and negative feedback affecting learning) and three themes (analytical) relating to the third research question (hierarchy, justification and inadequacy of the trainer).

\section{Research question one: what forms of positive and negative feedback are surgical trainees exposed to in the operating theatre?}

All respondents could provide incidences of both positive and negative feedback in the operating theatre. Given that all respondents received preinterview information at least 24 hours before the interview took place, this allowed respondents time to think about their answers. However, a number of respondents found that positive feedback, in particular very positive feedback (as defined by the interviewer), was a rare occurrence and examples were often many months old. Respondents did comment that feedback was more valued if it came from a consultant rather than a peer. In addition, if positive comments came from individuals who did not often give praise, they seemed to have added value to the individual. Types of positive feedback took of one of three main forms:

Continuous reinforcement:

...the trainer was praising me more for being able to follow their instructions very carefully, I think that is why it went well. (ID 2)

Giving responsibility:

I considered them an excellent trainer, very motivating, giving you enough responsibility and things to do appropriate at your level, takes over at difficult times and explains as well why they take over for example, 'this is the part I need to do', because that is really important and when the trainer says as well, 'I don't want to decrease your confidence by giving you those difficult parts so I will give you appropriate stuff on the operation at your level'. There's reasoning behind why they do certain things and I think it creates a very friendly learning environment. (ID 4)

Quiet encouragement:

He was like, 'you're progressing slowly but steadily, I'm going to stay back and I'm going to just carefully look, the support that $I$, the fact that he was there if things were not, if things were going out of hand and then he was keeping an eye on me which was the encouragement that I needed, I guess for that particular case. (ID 3)

Many respondents found it easier to recall specific accounts of negative feedback as they felt it had a more lasting impression. There was a greater variation of types of negative feedback given by trainees, as opposed to positive (table 1).

\section{Research question two: how can positive or negative verbal feedback affect a surgeons' training and personal development?}

This question generated a number of subthemes in relation to both positive and negative feedback. With regard to the effects of positive feedback, two themes were identified in relation to this question: positive feedback increasing the feeling of self-worth and positive feedback affecting learning. Regarding the theme of positive feedback increasing the feeling of self-worth, this generated five subthemes. Examples of each sub theme are presented (table 2). To illustrate this theme in more depth, the findings of one narrative will be presented. This narrative demonstrates how both positive and negative feedback can have an effect on training and development. 
Table 1 Participant's personal examples of negative feedback in the operating theatre

\section{Type of negative feedback}

Criticism

Victimisation

\section{Illustrative quote}

'A particular trainer who was quick to, again not someone from whom you hear positive feedback very often but who was very quick to criticise pretty much anything and everything about the way you work'. (ID 1)

'It became a very personal attack about a lack of interest, a lack of effort and lots of things which weren't really particularly fair. At the same time as then to concentrate on operating and I just found that whole sort of case uncomfortable'. (ID 9)

\begin{tabular}{|c|c|}
\hline Undermining & $\begin{array}{l}\text { 'He said (the trainer) something on the lines of, I showed you how to do it last time and it's quite } \\
\text { disappointing that you still haven't learned'. (ID 5) }\end{array}$ \\
\hline Poor communication & $\begin{array}{l}\text { 'I have sat down with this trainer on multiple occasions following these incidents and still been left } \\
\text { wondering why, wondering what I was doing wrong...' (ID 2) }\end{array}$ \\
\hline $\begin{array}{l}\text { Condescending } \\
\text { remarks }\end{array}$ & $\begin{array}{l}\text { 'If I'd had my twelve-year-old boy here, my twelve-year-old son, he would do a better job of the } \\
\text { procedure than you right now'. (ID 11) }\end{array}$ \\
\hline Swearing & $\begin{array}{l}\text { 'He was like what the } f^{* *} k \text { are you doing, why are you playing around with the laparoscope...this is } \\
\text { an emergency patient that unwell why didn't you just do it open and, and he just, and he just walked } \\
\text { away'. (ID 3) }\end{array}$ \\
\hline Physical abuse & $\begin{array}{l}\text { 'I was just trying to be a dynamic assistant and retract the tissue when he hit me on my wrist with a } \\
\text { Langenbeck retractor'. (ID 6) }\end{array}$ \\
\hline $\begin{array}{l}\text { Trainer creating a bad } \\
\text { atmosphere }\end{array}$ & $\begin{array}{l}\text { 'It was a tense environment and everyone was tense because the surgeon had been, just generally } \\
\text { being angry and then he shouted to me 'stop shaking'. (ID 4) }\end{array}$ \\
\hline Repeat offender & $\begin{array}{l}\text { 'He has a reputation for being a generally a bully and I kind of knew that before going there, but I } \\
\text { hadn't realised how bad he was until I actually got there. The first time he met me he started off by } \\
\text { slagging off the previous trainee that he had for a year, and how terrible and how lazy he was'. (ID 11) }\end{array}$ \\
\hline
\end{tabular}

ID, identification.

John (pseudonym) is a senior surgical trainee with many years of experience in the operating theatre. All quotations are presented verbatim. John recounts an event in relation to an operation he performed under supervision. The environment was relaxed and perfectly 'set-up' for a training experience. '...[T]he theatre list was running to time and the surgeon, the consultant was just relaxed and turned the operation over to me straight away and

Table 2 Examples of how positive feedback can increase feeling of self-worth

\section{Forms of positive development that increase feelings of self-worth}

Increased self-worth

Increased confidence

Positive reinforcement

How trainees want to be perceived as trainers themselves

Empowerment

\section{Illustrative quote}

'... It increases your confidence, it makes you want to do it again and it's also an ego thing, it makes you want to hear it again'. (ID 2)

'He made a comment that he didn't feel he was having to work very hard or think very hard, and that made me feel good and the next time I did that procedure I was more confident going into the operation'. (ID 12)

'I think I am quite, what's the word, not bashful but I don't think of myself as anything particularly special. I think of myself as a good doctor, I try to be as good as I can. I think I am just as what should be expected of me, do you know what I mean. I don't think anything I do is above and beyond what I should be doing so it is nice to get the positive feedback because actually you think, "maybe I am doing alright"'. (ID 6)

'...I think it's shaped a little bit of how I train, it's implications and just taking people through simple things, appendixes and things, and trying to just, if there are problems just stay around and be calm and treat other people in the same way'. (ID 9)

'... I've said this before - there are surgeons that l've trained with who I almost operate outside of what I thought I was capable of doing, we all have a vague idea of where we feel competent and we feel like "mm l'm not able to do this part of the operation". I think there are surgeons who bring out the best in me to the point where I feel like "God I didn't think I could do all that part of the operation"'. (ID 7)

ID, identification. 
said "you do this and I'll just assist and guide you". John stated that feedback containing superlatives or excessive praise was not necessary; it was subtle pointers that were beneficial while he was operating. 'I think what makes the biggest difference is it's not just the profound statements of the detail that they go into but very simple things like the continued positive feedback, just small words like "good" and "yep that's the right plane" and "nice yes I like that, keep going" '. John later explained why positive feedback relaxed him though also created a desire to perform and impress. 'So very little subtle things as you're going through the operation and it builds your confidence because you are quite nervous and anxious at the beginning of an operation, because you do feel a little bit like you're judged and you want to be able to do these operations and stuff and you want to do well and I think that just again relaxed me'. John, like many respondents, said that positive feedback improved his operative performance. 'When you're getting those little bits of positive feedback your confidence just grows. I've said this before - there are surgeons that I've trained with who I almost operate outside of what I thought I was capable of doing'. John, also states that positive feedback was crucial in his career choice, in particular his subspecialty choice. ' $I$ 'm sure my decision to come into [removed] surgery was based on positive experiences whilst training with (removed) surgeons... we all start out as generalists, we all have an inkling as to what we enjoy most, it can be experiences like that, operations like that, that enhance relationships with your bosses'. However, when it came to the effects of negative feedback, John's reaction was quite different; it was almost a mirror opposite. The environment was tense from the beginning. 'So I'd got in early as you do and I consented the patient, I knew the case, I'd looked at the scans and it was a negative experience... there was no, this might sound silly, no gratitude or acknowledgement that you'd got in early and done the consent and put the catheter in and done the huge checklist and things, and that's fine you know I'm thick-skinned enough not to worry about those sort of things. But that was the way in which things continued and there was a part of the operation when you get the dawning realisation that you're not going to get to do any of it and the educational component from that operation is going to be diminished'. John went on to describe that he was given barely anything to do in this operation and was continually undermined with condescending remarks. 'You feel like really sort of almost embarrassed because you're in a theatre full of people who know you or you spend time with and it's almost like they speak to you like a child really'. Akin to many other trainees, John felt powerless to speak up, but the effects of negative feedback did have an apparent result in a lack of selfworth. 'You don't want to sort of create a scene or anything but it makes you feel incompetent basically'.

Concerning the theme of the positive feedback effect on learning, this generated four subthemes. Individual examples of these subthemes are presented (table 3 ).

Answering the same research question from a negative feedback perspective gave reflective themes: negative feedback can decrease the feeling of self-worth and negative feedback affecting learning. Subthemes were however different. Subthemes of each are all presented in table 4.

\section{Research question three: why does negative feedback exist in} the operating theatre environment?

Three themes relating to the third research question (hierarchy, justification and inadequacy of the trainer) attempted to answer this question. During narrative interviews, respondents tended to discuss what was

Table 3 Subthemes identified within the theme of the positive effects of feedback on learning

\section{Forms of positive \\ effects on learning Illustrative quote}

Making the needs of '...the consultant purposely at the end made sure we sat down, once I had written the op notes, to trainees a priority discuss it. You know, what went well, what could I have done better, made me say how I thought it had gone before they sort of critiqued and then had more of a discussion around it'. (ID 6)

Enhancement of the 'when you are given such a positive statement it makes you believe that you can do it, it makes you learning experience believe that you can do it again next time. It very much increases how confident you are about what you are doing. All of that kind of thing flashes through your head initially. It also makes you want to do it again'. (ID 1)

Increased willingness 'I think it certainly means you look forward to going in to theatre a little bit more, I think it built, what it to learn and work builds is the bond between you and the trainer, so you've had some positive feedback you then want to with that trainer go and you want to do well for them next time and you want the same thing'. (ID 4)

Positive effects on 'I changed my mind about my particular sub-specialty relatively late and I changed it based on... I didn't career choices change it based on how negative he was, I changed it based on the positive experience of my specialty at a later date'. (ID 1)

Increased feeling of '...I had put a stitch through the small bowel and he wasn't angry, he was, well he was disappointed with
support
me because I was doing well and could see that he felt that I had let him down but, but he said "well, you
on and we finished and we have operated since and we haven't had an issue, we have actually a very
good relationship and we talk about that event, we jest about that event and we move on'. (ID 3)

ID, identification. 


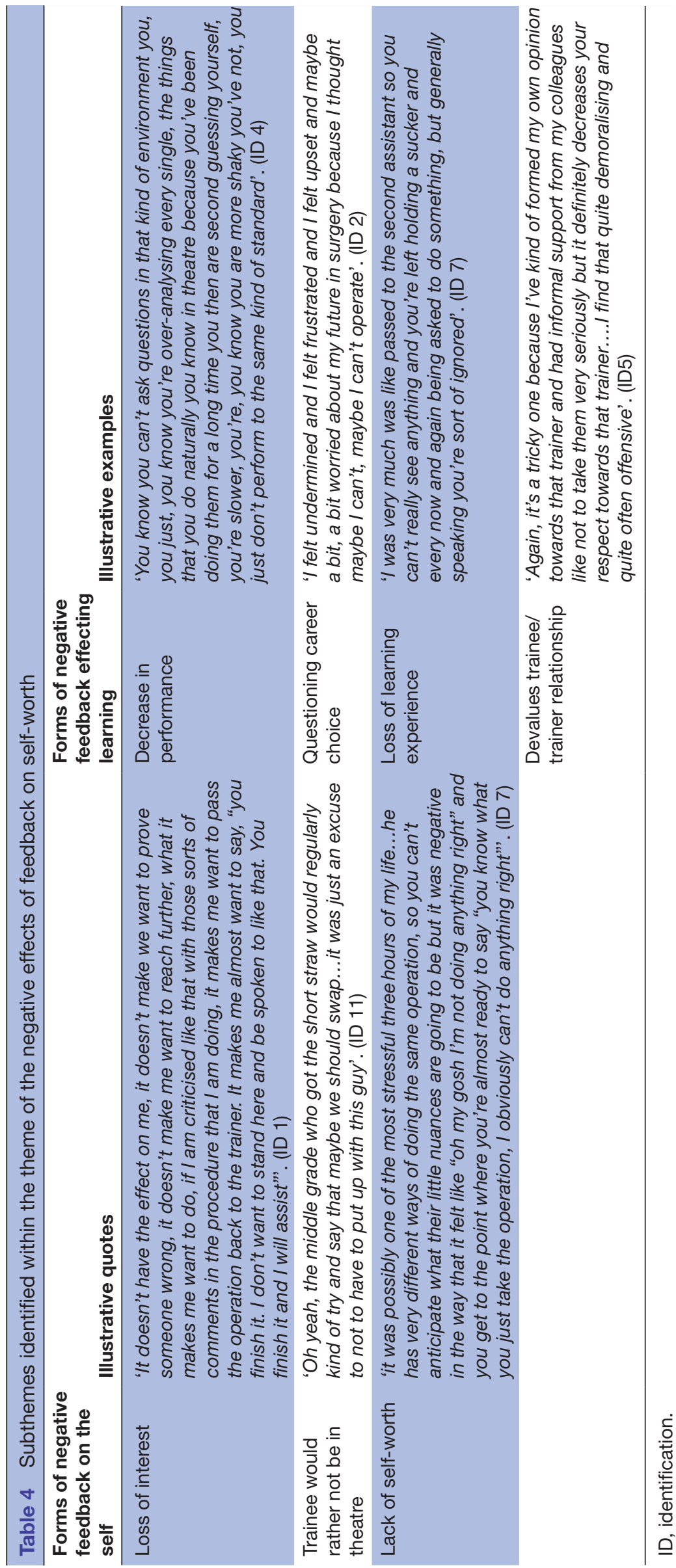


Table 5 Examples of hierarchy within surgery

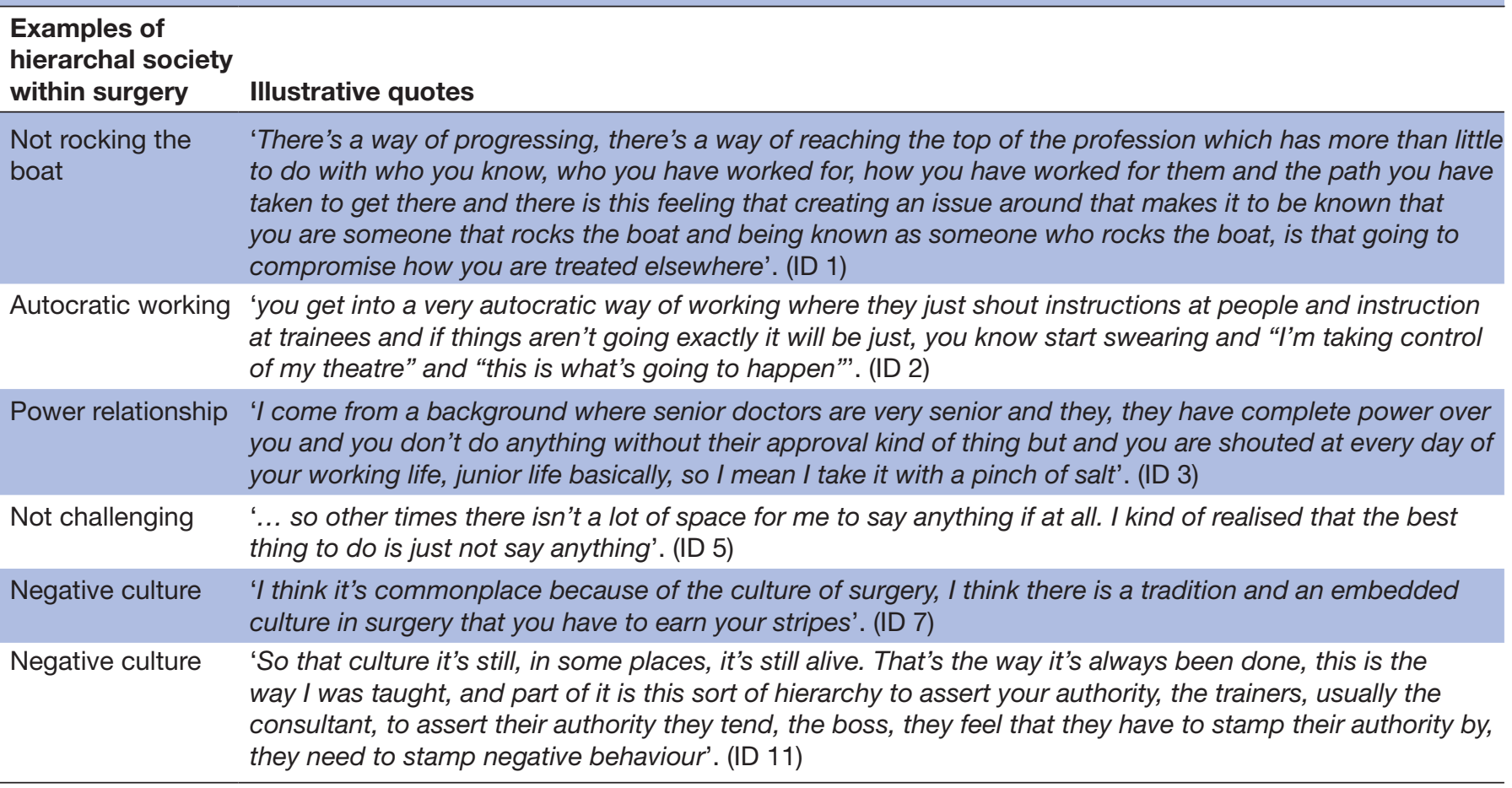

ID, identification.

deemed significant negative examples of feedback received with its subsequent effects. The vast majority of trainees said that there was no place for this form of feedback in the operating theatre environment as it has predominately negative effects on the individual with very limited educational benefit.

I couldn't figure what I'd been doing wrong, so there's nothing you can possibly change about that, it just made me angry, just made me doubt my own ability. (I) just didn't really find it helpful at all. (ID 2)

Hierarchy, or autocratic leadership as one respondent described it, was thought to be a major reason for negative feedback to persist in the operating theatre and remain unchallenged. Relevant examples are given (table 5). All trainees who discussed why this remained unchallenged were reluctant in speaking out as they feared for their own career. It was felt if trainees spoke up that the trainer involved could cause significant disruption for their futures.

[Name] behaviour is like that, there's been no change in a long period of time. You saying something is very unlikely to change that, but it might change your career, so is it actually worth it? (ID 4)

It was acknowledged by all respondents that the extremes of negative feedback were from individuals who had a reputation for doing so to others. As a result, the impact of such negativity was often lessened.
The whole theatre, the nurses and the anaesthetists and everybody else, seem to be winking at you when this one starts screaming. It makes it easier to deal with it. (ID 5)

As a consequence, respect for the trainer was reduced (table 4). There were trainees who felt that in some instances negative feedback was justified; for example, if trainees had misjudged the clinical situation, it was appropriate for the trainer to be abrupt. Furthermore, there was acknowledgement from trainees that it is easier for the trainer to do the operation themselves.

I think in all these situations the context of that relationship is that basically it's easier for the trainer/consultant to do the operation themselves especially when it isn't challenging in any way, so in one sense they are putting themselves out to walk you through those different steps as you are on your learning curve. (ID 12)

This may account for trainees accepting a degree of negative feedback from trainers. A number of trainees felt that trainers gave negative feedback simply because they were not good trainers and did not know how to train. Consultants were given the title of trainers without formal training and some seemed to have no desire to teach.

I think a lot of people get labelled as trainers, who are not trainers in any sense of the word. So they have no interest in training people, and they've had no education in training people so they don't know how to teach. (ID 11)

Other reasons for why negative feedback exists in the operating theatre environment were believed to occur as 
the trainers themselves are under stress, either from the operation, the job as a whole or personal issues.

I think often times when trainers come out with comments like that which are slightly inconsistent with what's going on at that time and place, you're sometimes left wondering in retrospect what's been going on in their own lives over the preceding two hours. (ID 12)

\section{DISCUSSION}

To our knowledge, this is the first study that describes trainees' experiences of perceived positive and negative feedback in the operating theatre and reports the effects on their confidence, well-being and further development. It is noteworthy that all trainees initially struggled to give recent examples of feedback, in particular positive examples. This may be that they wanted to provide examples that were significant to them or possibly that there is a general lack of regular trainer feedback or that some trainers have a tendency to criticise trainees in the operating theatre rather than praise them or indeed that trainees are more likely to recall the negative. The findings in this study are in keeping with previous research, ${ }^{20}$ which concluded that feedback was rarely given to trainees after an activity and often with a lower degree of positive observation in comparison to trainer's perceptions.

Nevertheless, trainees were able to provide examples of positive feedback, although this tended to be less dramatic with fewer variations compared with negative feedback. Trainees in this study reported that a positive theatre environment, created when the needs of a trainee were made a priority within in a supportive environment, with positive feedback, appeared to have a favourable impact on their perceptions of learning. This was achieved through positive or even superlative comments, without feelings of unjustified criticism and where trainees had a clear idea of what the learning objectives were going to be during each case. The respondents claimed that this helped them relax, and many stated that they felt it enhanced their operative performance. Consequently, trainees expressed an increased willingness to learn and work further with a trainer with whom they felt more supported. This is supported by research that highlights the ability of trainers to create a positive learning environment, by supporting trainees to develop self-regulation and error detection skills. ${ }^{21}$ This supportive role of the trainer may enable the trainee to encourage them to leave their 'comfort zone', enabling them to perform more complex operations than they previously thought with the aim of furthering their surgical development. ${ }^{22}$

All trainees reported they had experienced what they felt to be significant and unjustified negative feedback in either the trainers behaviour or mode of delivery. Many believed this to have a negative impact on their training and be of minimal educational benefit. Similar findings were reported in a study focused on learning a new language ${ }^{23}$ where negative feedback was detrimental to learning and motivation. Interestingly, trainees found negative events much easier to recall, which is also in concordance with previously published literature. ${ }^{24}$ This may be due to the longer and more lasting impression of negative feedback in the operating theatre compared with positive feedback. Negative emotions that can be associated with negative feedback require more thinking and processing than positive events. ${ }^{25}$ Therefore, trainees tend to reflect on these negative events more, which makes them easier to recall. ${ }^{26}$ The forms of negative feedback were more varied, ranging from condescending remarks to physical abuse. Furthermore, many trainees felt that as a consequence, their performance in the operating theatre suffered; this could be due to trainees focusing more on the negative responses that were given rather than the task at hand. The consequential effect of negative feedback could be detrimental to their learning and performance. This is contrary to the work undertaken by various researchers ${ }^{9} 27$ who demonstrated a potency of negative compared with positive feedback. However, it is important to note a key point of such research ${ }^{9}$ was only observed in high self-esteem individuals. It is therefore possible that, in this study, persistent negative feedback may lower the self-esteem of surgical trainees.

It is important to note that certain learning events within the operating theatre require constructive criticism and corrective feedback. A highlighted example in this study was of iatrogenic injury to the small bowel to a patient being operated on by the trainee. The trainee reported that the trainer provided support and constructive advice, without undue criticism. Feedback was given in such a way that the positive professional relationship was maintained, and the feedback was not perceived to be detrimental to the learning experience. Indeed, Hamad et $a l^{28}$ demonstrated that feedback after small bowel anastomosis helped to reduce further adverse events. There has been research highlighting significant differences regarding feedback delivery in the operating theatre between the trainee and the trainer. ${ }^{29}$ The author concluded that although both the trainer and trainee agree that feedback is vital for a surgeon's development, there were large discrepancies between these groups about the perceived quality of feedback that the trainer delivers. However, we believe that negative feedback, if delivered in a constructive manner and provided in a positive learning environment, is important, as this will also enable the trainee to improve and learn from such adverse events.

In this study, negative learning environments created by trainers following incidents of shouting or swearing highlighted the power relationship between the trainer and trainee and inhibited the likelihood of a trainee speaking up. When this environment was compounded by continued negative feedback, this was reported to impair their performance. These findings are consistent with previous findings ${ }^{30}$ where, although harm to patients was not noted as a result of the feedback, this does not exclude detrimental events happening 
in the future following persistent negative feedback. Lingard et $a l^{31}$ reported that at least $60 \%$ of major adverse events within the operating theatre are a result of poor communication. The data highlight a lack of effective communication, and failures from the trainers were a source of frustration for the trainees. Of note was a perception that some trainees felt they did not receive adequate information regarding the operation they were undertaking or how to perform it more effectively. Indeed, a large meta-analysis ${ }^{6}$ has demonstrated that effective communication is one of the most powerful forms of feedback. The data illustrate an apparent lack of quality feedback and signifies a missed opportunity to enhance the learning experience with a failure to reduce the gap between current and desired understanding. ${ }^{1}$ Although trainers' views were not collected within this study, their busy and stressful workload coupled with the absence of formal feedback training may account for these experiences and communication breakdowns. $^{32}$

Both positive and negative forms of feedback appeared to influence the potential career choice of the trainees. At a time when doctors in the UK are in short supply, this is an important finding. Of greater concern is the finding that following negative feedback, some trainees stated that they had contemplated leaving surgery. This study identified that some trainers were repeated offenders as regards using negative behaviours alongside feedback that was at times more abusive than constructive. The manner in which feedback is delivered is important as negative feedback that is not delivered in a constructive manner can be perceived by some as undermining or bullying. These complex issues are still considered taboo, resulting with these issues being ignored and under-reported. ${ }^{33}$ The Royal College of Surgeons of Edinburgh reported $60 \%$ of trainees had personally been at the receiving end of workplace bullying with $94 \%$ having observed it.

Trainees did not challenge or report such behaviours. There was a belief by the trainees that any challenge or complaint would impact negatively on their future career. Undermining and bullying behaviours have a long history within surgery, ${ }^{34}$ with the 'surgical culture' offered as an excuse to allow acceptance of certain actions in the operating theatre that would otherwise not be tolerated. ${ }^{35}$ The tolerance of negative behaviour from trainers is in keeping with previous research. ${ }^{34} 35$ This reluctance to speak out against what trainees believe to be unjustified negative feedback that is undermining rather than corrective, and continue to work professionally, demonstrates resilience within the trainee. This is a key feature of adult learning. As the surgical trainees mature, their motivation to learn is internal. ${ }^{36}$ Trainees continued desire to learn, and work is not completely hindered by the external effects of extreme forms of negative feedback provided by the trainer. However, trainees did acknowledge that this bullying type behaviour was inappropriate. Many said that they would use these examples as evidence of how not to train in future. Behaviour within theatre is not readily observed by outsiders or passersby, therefore unacceptable behaviour may persist unchecked in this microcosm as challenge from juniors is difficult due to the perceived hierarchy. Older generations were exposed to different styles of feedback, some of which are no longer acceptable, and the current cohort of trainees seem to want to break away from this type of negative feedback and the cycle of a 'transgenerational' legacy. ${ }^{37}$ Nonetheless, we need to consider the perspective of the trainer who takes on the role of 'expert' and is expected to impart skills to the novice while maintaining full responsibility for the patient and the outcome of the surgery. The trainer will on occasion be unfamiliar with the trainee and their level of skill and perceive additional risk in sharing the surgery. Additionally, how trainers respond to and manage trainees may depend on their own level of skill and confidence. Those less skilled or confident may experience more stress, and this may manifest itself as inappropriate feedback.

There is evidence within this study of excellent trainers. However, this appears to coexist with feedback from some trainers that is both negative, abusive and impacts negatively on future career plans. The General Medical Council, as a consequence of Lord Patel's report $(2010),{ }^{38}$ which highlighted a deficiency in training, is planning to put in a formalised trainer-approved system for all trainers, and the findings from this study would support this initiative.

\section{Reflexivity and rigour of this research}

Reflexivity is an important process in acknowledging the role of the researcher and how this may influence what is 'seen' in the data and to permit confirmability. ${ }^{39-41}$ One of the authors is a current surgical trainee (DK) who has experienced both positive and negative verbal feedback in the operating theatre. Such experiences have been a source of motivation for this topic and also added an understanding of the context of practice. The potential of shared experiences or context enables the researchers to accurately portray the meanings made by fellow surgical trainees. ${ }^{42}$ However, we were mindful of how personal values and perceptions could affect data analysis. ${ }^{43}$ We therefore took a number of steps to ensure transferability of findings. ${ }^{44}$ The aim was to ensure the findings represented the views (constructs) of the interviewees. This was achieved by the narrative interview techniques and analysis that permitted repeated reviewing of data to identify emerging themes. This ensured that we remained 'true' to the participants' accounts of the effects of feedback. Additionally, the use of rich verbatim quotes allows the reader to make their own judgement as to whether coded themes reflect accurately the accounts of the participant. Furthermore, identification of themes was supported as all transcripts were read and coded by the coauthor of this study (JI) who is not in the surgical profession. ${ }^{45} 46$ 


\section{Future work}

This small scale study calls for a larger study across the UK looking into the personal effects of feedback on surgical trainees and calls for further training to support trainers to deliver effective feedback. Any such training intervention should be robustly evaluated. In addition, discussion with trainers is needed to gain their perspective. We believe that trainers and trainees need to have a more open and frank discussion regarding the effects that feedback can have on an individual's well-being.

\section{CONCLUSION}

This study has put forward a wide range of different experiences of positive and negative feedback within the operating theatre. There is evidence of excellent trainers. Positive feedback can enable trainees to leave their 'comfort zone', enabling them to perform more complex operations than they previously thought which can further their surgical development.

However, some feedback can be perceived as bullying and can have a very negative effect, potentially leading to missed learning opportunities'. ${ }^{47}$ Following the significant time restraints set by the European Working Time Directive, this is a concern. A power relationship is still evident in surgery, with some forms of feedback apparently damaging performance, at times in our study leading trainees to have thoughts of pursuing an alternative career. We need to consider why negative feedback exists in theatre, and understanding why this occurs may help us to identify how to change and improve the training experience. However, we also acknowledge the importance of administering negative feedback that is constructive and corrective. If this is given in a supportive environment, this can enhance the learning process without undermining the trainee. Increasing personal awareness of these issues in trainers and supporting them to manage competing responsibilities to the patient, and the trainee in a safe environment should be the goal of training.

Acknowledgements The authors would like to thank Charlotte Rothwell for her help with interview transcription.

Contributors DK's substantial contribution involved design, data collection, analysis and write up of this article.Jl's substantial contribution involved design, data analysis, write up and revision of this article. Both authors are in agreement for this final version to be published and agree to be accountable for all aspects of this work.

Funding This research received no specific grant from any funding agency in the public, commercial or not-for-profit sectors.

Competing interests None declared.

Patient consent Obtained.

Ethics approval Ethical approval was gained from Newcastle University.

Provenance and peer review Not commissioned; externally peer reviewed.

Data sharing statement Copies of coded interview transcriptions and all raw data that was thematically analysed are available upon request.

Open Access This is an Open Access article distributed in accordance with the Creative Commons Attribution Non Commercial (CC BY-NC 4.0) license, which permits others to distribute, remix, adapt, build upon this work non-commercially, and license their derivative works on different terms, provided the original work is properly cited and the use is non-commercial. See: http://creativecommons.org/ licenses/by-nc/4.0/

(C) Article author(s) (or their employer(s) unless otherwise stated in the text of the article) 2018. All rights reserved. No commercial use is permitted unless otherwise expressly granted.

\section{REFERENCES}

1. Hattie J, Timperley H. The power of feedback. Rev Educ Res 2007;77:81-112.

2. Ende J. Feedback in clinical medical education. JAMA 1983;250:777-81.

3. Bucher R, Stelling JG. Becoming professional. Beverly Hills, CA: Sage Publications Inc, 1977:194-204.

4. Deci EL, Koestner R, Ryan RM. A meta-analytic review of experiments examining the effects of extrinsic rewards on intrinsic motivation. Psychol Bull 1999;125:627-68.

5. Ilgen $D$, Davis $C$. Bearing bad news: reactions to negative performance feedback. Appl Psychol 2000;49:550-65.

6. Kluger AN, DeNisi A. The effects of feedback interventions on performance: a historical review, a meta-analysis, and a preliminary feedback intervention theory. Psychol Bull 1996:119:254-84.

7. Kannappan A, Yip DT, Lodhia NA, et al. The effect of positive and negative verbal feedback on surgical skills performance and motivation. J Surg Educ2012;69:798-801.

8. Spanager L, Dieckmann P, Beier-Holgersen R, et al. Comprehensive feedback on trainee surgeons' non-technical skills. Int J Med Educ 2015;6:4-11.

9. Brockner J, Derr WR, Laing WN. Self-esteem and reactions to negative feedback: toward greater generalizability. J Res Pers 1987;21:318-33.

10. Moreland RL, Sweeney PD. Self-expectancies and reactions to evaluations of personal performance. J Pers 1984;52:156-76.

11. Kernis MH, Brockner J, Frankel BS. Self-esteem and reactions to failure: the mediating role of overgeneralization. J Pers Soc Psychol 1989;57:707-14.

12. Mattick K, Kelly N, Rees C. A window into the lives of junior doctors: narrative interviews exploring antimicrobial prescribing experiences. $J$ Antimicrob Chemother 2014;69:2274-83.

13. Robson C. Real world research. 3rd edn. Chichester: Wiley, 2011.

14. Sargeant J, Mann K, Sinclair D, et al. Understanding the influence of emotions and reflection upon multi-source feedback acceptance and use. Adv Health Sci Educ Theory Pract 2008;13:275-88.

15. Crotty M. The foundations of social research. Meaning and perspective in the research process. London: Sage Publications, 2003.

16. Saedon $\mathrm{H}$. An analysis of ophthalmology trainees' perceptions of feedback for cataract surgery training. Clin Ophthalmol 2014:8:43-7.

17. Adler PA. Adler P. In: Baker SE, Edwards R, eds. How many qualitative interviews is enough? Expert voices and early career reflections on sampling and cases in qualitative research. Review paper. Southampton: National Centre for Research Methods, 2012.

18. Richards R, Polkinghorne D. Review of narrative knowing and the human sciences. Am J Sociol 1989;95:258-60.

19. Ritchie J, Spencer $L$. Qualitative data analysis for applied policy research. In: Bryman A, Burgess RG, eds. Analyzing qualitative data Routledge. London, 1994.

20. Sender Liberman A, Liberman M, Steinert $Y$, et al. Surgery residents and attending surgeons have different perceptions of feedback. Med Teach 2005;27:470-2.

21. Hattie J, Biggs J, Purdie N. Effects of learning skills interventions on student learning: a meta-analysis. Rev Educ Res 1996;66:99-136.

22. Vygotsky LS. 1978 Mind in Society. In: Sweller J, Cognitive load during problem solving: effects on learning, cognitive science. Cambridge, MA: Harvard University Press, 1988;12:257-85.

23. Kim JH. Issues of corrective feedback in second language acquisition, 2004.

24. Baumeister RF, Cairns KJ. Repression and self-presentation: when audiences interfere with self-deceptive strategies. J Pers Soc Psychol 1992:62:851-62.

25. Nass C. The man who lied to his laptop: what machines teach us about human relationships, 2010.

26. Brunit S, Huguet P, Monteil JM. Performance feedback and selffocused attention in the classroom: When past and present interact. Social Psychology of Education 2000;3:277-93.

27. Campbell JD, Fairey P. Effects of self-esteem, hypothetical explanations, and verbalization of expectancies on future performance. J Pers Soc Psychol 1985;48:1097-111. 
28. Hamad GG, Brown MT, Clavijo-Alvarez JA, et al. Postoperative video debriefing reduces technical errors in laparoscopic surgery. Am J Surg 2007;194:110-4.

29. Jensen AR, Wright AS, Kim S, et al. Educational feedback in the operating room: a gap between resident and faculty perceptions. Am J Surg 2012;204:248-55.

30. Matsui T, Okada A, Inoshita O. Mechanism of feedback affecting task performance. Organ Behav Hum Perform1983;31:114-22.

31. Lingard L, Espin S, Whyte S, et al. Communication failures in the operating room: an observational classification of recurrent types and effects. Qual Saf Health Care 2004;13:330-4.

32. LeBlanc VR. The effects of acute stress on performance: implications for health professions education. Acad Med 2009;84:S25-33.

33. Carter M, Thompson N, Crampton P, et al. Workplace bullying in the UK NHS: a questionnaire and interview study on prevalence, impact and barriers to reporting. BMJ Open 2013;3:e002628.

34. Musselman LJ, MacRae HM, Reznick RK, et al. 'You learn better under the gun': intimidation and harassment in surgical education. Med Educ 2005;39:926-34.

35. Myers MF. Abuse of residents: it's time to take action. CMAJ 1996;154:1705-8.

36. Knowles M. The adult learner: a neglected species. 3rd edn. Houston, TX: Gulf Publishing, 1984.

37. Kassebaum DG, Cutler ER. On the culture of student abuse in medical school. Acad Med 1998;73:1149-58.
38. General Medical Council. 2010. Final Report of the Education and Training Regulation Policy Review: Recommendations and Options for the Future Regulation of Education and Training.

39. Cutcliffe JR, McKenna HP. When do we know that we know? Considering the truth of research findings and the craft of qualitative research. Int J Nurs Stud 2002;39:611-8.

40. Kingdon C. Reflexivity: not just a qualitative methodological research tool. Br J Midwifery 2005;13:622-7.

41. Pillow W. Confession, catharsis, or cure? Rethinking the uses of reflexivity as methodological power in qualitative research. Int $J$ Qual Stud Educ 2003;16:175-96.

42. Morrow SL. Honor and respect: feminist collaborative research with sexually abused women. In: Fischer CT, ed. Qualitative research methods for psychologists: introduction through empirical studies. 1st edn. London: Elsevier, 2006:143-72.

43. Gerrish K, Lacey A eds. The Research Process in Nursing. 5th edn. Oxford: Blackwell Publishing, 2006.

44. Bryman A. Social research methods. 3 edn. New York, NY: Oxford University Press, 2008.

45. Denzin NK. Sociological Methods. New York: McGraw-Hill, 1978.

46. Patton $M Q$. Enhancing the quality and credibility of qualitative analysis. Health Serv Res 1999;34:1189-208.

47. Temple J. Time for Training: a Review of the impact of the European Working Time Directive on the quality of training. 2010 https://www. hee.nhs.uk/sites/default/files/documents/Timefortraining\%report_0. pdf (accessed 20 Jul 2017). 